\title{
THE CHEMICAL CONTROL OF PESTS OF STORED AGRICULTURAL PRODUCE
}

\author{
G. A. H. Helson \\ Department of Agriculture, Wellington
}

Summary

Throughout the history of agriculture, stored produce pests have inhabited man's granaries. The result has been their world-wide distribution. In New Zealand, many, if not all, have been recorded from time to time and numbers have become established, but the cool, temperate, insular climate has prevented most of them from rising to plague numbers. In recent times, however, the introduction of farm grain-storage silos has seen an increase in mite infestations and that of certain Coleoptera. Control of these pests has been largely confined to sound hygiene and fumigation.

\section{INTRODUCTION}

EVER SINCE the storage of agricultural produce began, man has been plagued with insect pests which between harvest and consumption devour as much as 25 to $30 \%$ of the crops he grows. These pests of stored products are now ubiquitous, having been transferred from country to country in the course of commerce. New Zealand is no exception, and now many cosmopolitan species of insects and mites infest our produce stores and bulk grain silos. Tetley (1950-51), Morrison (1956), and French (1965) have described various aspects of the problem, but the introduction in recent times of large numbers of grain-storage silos on farms, where much of the grain crops are now stored, has introduced a new facet. Fortunately, many of the pests are warm-climate insects, and as New Zealand is for the most part in the cool, temperate zone, its climate is not ideal for their development. Here their development is slowed down when compared with that in warmer climates, and this reduces the number of generations per year. Thus, the problem has not been as great as in some other countries.

\section{CHECK LIST OF SPECIES PRESENT IN NEW ZEALAND}

The following is a list of many of the pests of stored products known to occur in New Zealand (there may be others not listed here):

Anagastä kuehniella

Acarus siro

Acanthoscelides obtectus

Ahasverus advena

Blatella germanica

Cadra: cautella

Carpophilus dimidiatus

Cryptolestes ferrugineus

Dermestes maculatus

Dermestes lardarius

Ephestia elutella
Mediterranean flour moth

meal mite

bean weevil

foreign grain weevil

German cockroach

dried-fruit moth

rust-red grain beetle

hide beetle

larder beetle

tobacco moth 
Glycyphagus spp. Gnorimoschema operculella

Lasioderma serricorne

Liposcelis spp.

Lepinotus spp.

Mezium affine

Necrobia rufipes

Oryzaephilus surinamensis

Periplaneta americana

Plodia interpunctella

Ptinus clavipes

Ptinus tectus

Rhizopertha dominica

Stegobium paniceum

Sitophilus granarius

Sitophilus oryzae

Sitotroga cerealella

Tenebrio molitor

Tribolium confusum

Tribolium castaneum

Tenebroides mauritanicus

Trigonogenius globulus

Tyrophagus putrescentiae grain mite

potato tuber moth

tobacco beetle

psocids

psocids

spider beetle

red-legged ham beetle

saw-toothed grain beetle

American cockroach

Indian meal moth

spider beetle

spider beetle

lesser grain beetle

drug-store beetle

grain weevi

rice weevil

Angoumois maize moth

yellow mealworm

confused flour moth

flour moth

cadelle

spider beetle

Tyroglyphid mite

\section{PLACES OF INFESTATION}

Apart from the spoilage of agricultural produce in store for home consumption, pest-free agricultural produce is important to New Zealand internationally; for example, small seeds for export must be pest-free before export to obtain an international health certificate required by most importing countries. Again, mites taint grain, which makes it useless for fowl feed, though in some cases it might be suitable to feed to pigs. A survey carried out by French (1965) showed that a proportion of farm bulk wheat silos had mite infestations in the wheat. The survey also showed that mites were more prevalent than insect infestation in bulk grain, and that the two most common insect pests were weevils and beetles.

Differing groups of storage pests infest the various storehouses of agricultural produce, the main damage being caused by the larval stages of various species of moths and beetles as follows:

Flour mills: a suitable environment for such pests as meal mite, grain mites, Mediterranean flour moth, dried-fruit moth, tobacco moth, Indian meal moth, lesser grain beetle, grain and rice weevils, yellow mealworm, cadelle, and saw-toothed grain beetle. Regular fumigations are carried out for their control.

Maize stores and silos: grain mites, Angoumois maize moth, Mediterranean flour moth, Indian meal moth, and grain and rice weeviss.

Potatoes in store: attacked by potato tuber moth.

Tobacco stores: tobacco beetle, drug-store beetle, tobacco moth, and mites. Hide stores: spider beetles, larder beetles, hide beetle, and mites.

Seed stores: saw-toothed grain beetle, rust-red grain beetle, spider beetles, psocids, flour and meal moths, bean weevil, and mites.

Bulk grain stores (including farm silos): saw-toothed grain beetle, rustred grain beetle, grain and rice weevils, and mites. 


\section{CONTROL MEASURES}

Preventive

Fresh produce should not be mixed with that already in store. Secondhand bags and containers should never be used unless fumigated beforehand. Floors and walls of storerooms should be swept clean, preferably vacuumed with a commercial vacuum cleaner, particular attention being paid to cracks in the floors and walls, and foundations under floors should be cleared of all stored produce debris that may have fallen through cracks in the floorboards. Floors and walls may be sprayed with premiumgrade maldison or dichlorvos before the goods are received into store. Grain and seeds should have a moisture content of $15 \%$ or less (preferably about $12 \%$ ) on receipt into store, and in certain areas this will entail the use of driers. Grain or seed from a drier, however, must be cooled before it is stored in bulk (it may take warm bulk grain as long as 3 months to cool down); and grain in storage must be inspected regularly for condition, that is, "hot" spots and insect and mite infestation (Griffith, 1964).

\section{Chemical Control}

Chemical control is mostly confined to fumigation, because this is the only form of control which meets the requirements of the New Zealand Food and Drugs Regulations 1946 under the Food and Drugs Act 1969, relating to the treatment of stored foodstuffs offered for sale for human consumption.

Chemicals which can be used to control insects in stored produce include the following:

\section{Fumigants}

Methyl bromide: This is a gas at ordinary temperatures and pressures and is stored as a liquid in heavy cylinders under pressure. Its chief advantage is its ability to penetrate quickly and deeply in materials at normal atmospheric pressure, and at the end of the treatment its vapours dissipate rapidly and make possible the handling of bulk quantities.

It is non-inflammable and goods may be treated at temperatures down to $39^{\circ} \mathrm{F}\left(4^{\circ} \mathrm{C}\right)$. In insects its principal toxic effect is on the nervous system.

Precautions in its use are essential because it is a cumulative poison The Fumigation Regulations 1967 specify that it can only be applied under the supervision of an operator who holds a certificate of competence from a Medical Officer of Health.*

Carbon bisulphide: This is still the only fumigant used in certain parts of the world, but in many places it has been largely replaced by methyl bromide, as in New Zealand, with some exceptions-e.g., fumigation of potatoes in sheds. It is, however, a dangerous fire hazard and, because of its inflammability, naked lights must be kept well away during its use. It penetrates. well, and in other countries is often formulated in mixtures with non-inflammable ingredients for fumigating grain. It has a low boiling point and is toxic to man. Precautions in its use include storing cans or drums of liquid in cool, shaded, well-ventilated rooms, never under the direct sun. Contact of vapour with a steam pipe or an electric light bulb may be enough to ignite it. Even heat generated by its being struck by a heavy blow may set off an explosion. The spark from static electricity or from an electric motor is a cause of ignition. Therefore, great cirre must be used during fumigation (Table 1).

*For a schedule of respirators approved for use consult the local Medical Officer of Health. 


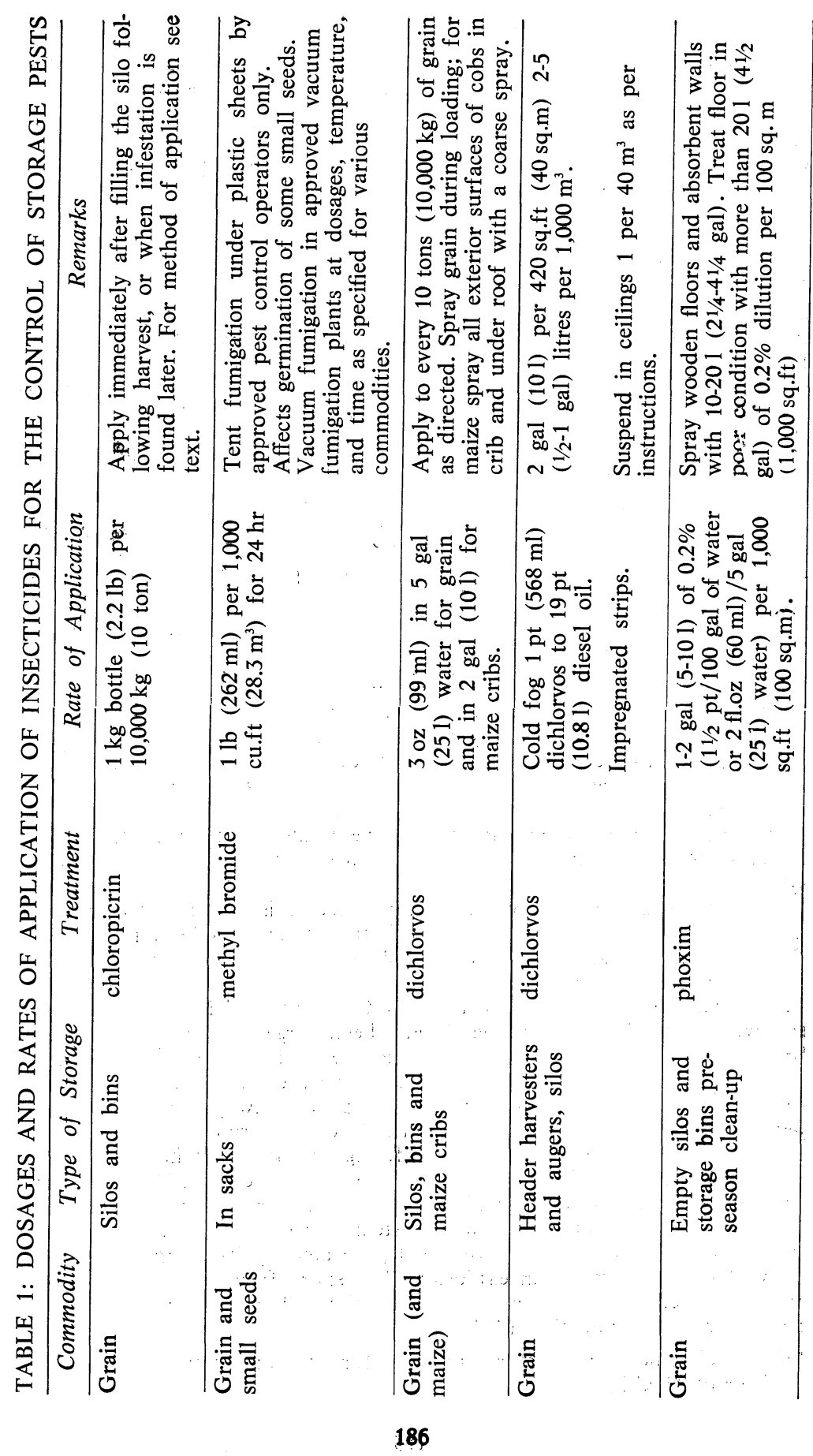




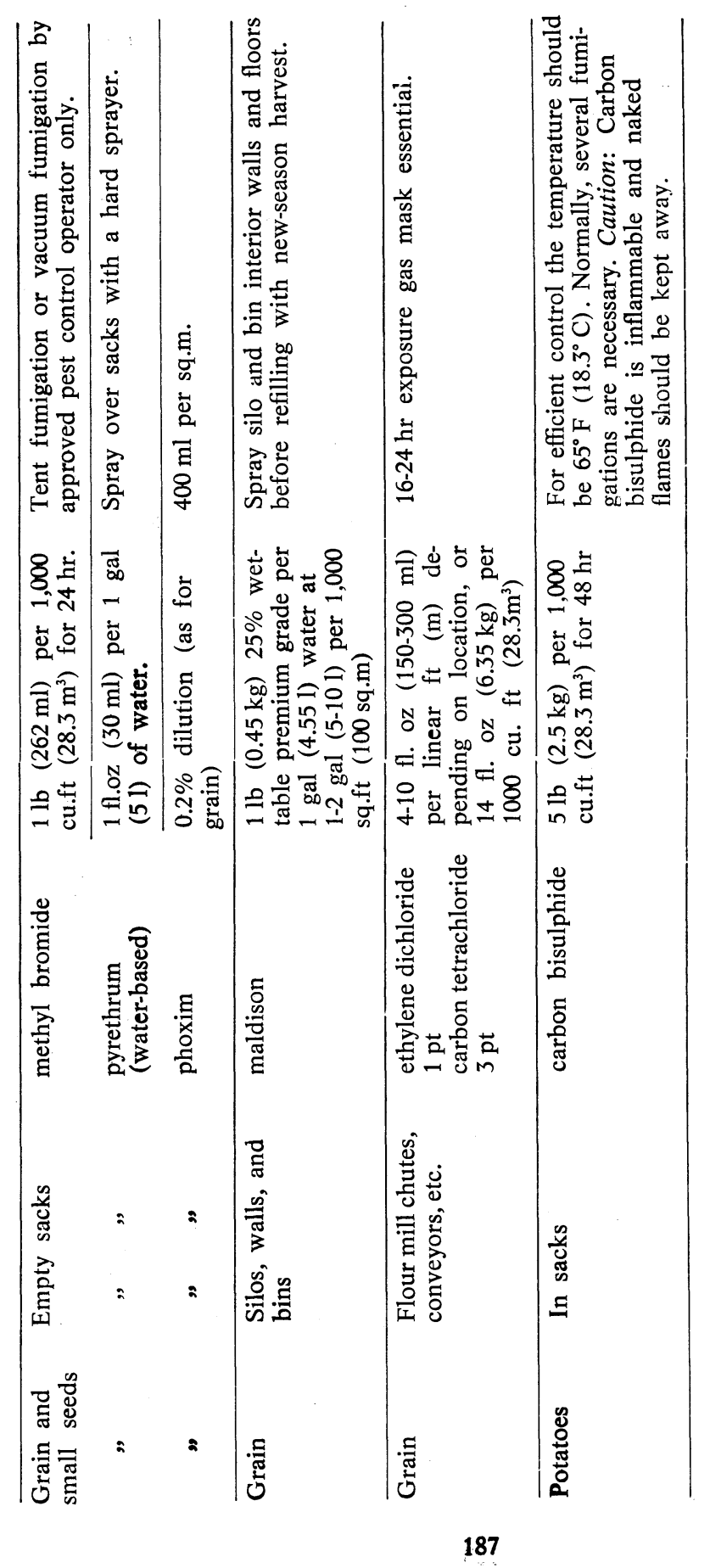


Chloropicrin: This is a powerful tear gas and one of the mist toxic to insects of the fumigants commonly used today. It is added in small quantities to methyl bromide to serve as a warning agent. Its disadvantage is that fumigated commodities are unpleasant to handle for some time after fumigation. For this reason, it is only used for fumigating bulk farm grain silos. It penetrates effectively into many materials, but it is corrosive to metals and care should be taken to protect metal surfaces and equipment during treatment. It is sold in bottles $(1 \mathrm{~kg})$ and these should be stored in a cool, safe, lock-up poison cupboard out of reach of children and not likely to get broken.

To fumigate a grain silo use a $1 \mathrm{~kg}(2.2 \mathrm{lb})$ bottle per 10 tons $(10,000$ $\mathrm{kg})$ of grain. Drive five $1 / 2$ in. $(12.7 \mathrm{~mm})$ to $3 / 4$ in. $(19 \mathrm{~mm})$ pipes $8 \mathrm{ft}$ $(2.5 \mathrm{~m})$ long, plus five more pipes $4 \mathrm{ft}(1.22 \mathrm{~m})$ long, down through the grain. Divide the total volume of chemical into 15 equal parts. Pour one part down each pipe, starting at the one farthest from the silo hatch and work toward the hatch. Use five parts as a surface application. Leave the grain undisturbed for at least 2 weeks.

Caution. At all times a respirator fitted with the correct canister must be worn.* While working inside the silo, have a companion outside to give help if required.

\section{Sprays}

Maldison: This is an organophosphate which can only be used to spray the walls of empty silos which have been thoroughly cleaned out of last season's remains before they are refilled with new-season grain. Premium grade should be used. Care must be taken not to apply it to grain, and in handling, because, like all organophosphates, it is poisonous to man. A respirator with the correct canister and fully protective clothing must be worn when using it. Doses are given in Table 1. If preferred, a $50 \%$ emulsifiable concentrate spray may be used at the rate of 1 pint $(570 \mathrm{ml})$ per 27 gal (123 l) of water per 1,000 sq.ft (100 sq.m) (Table 1).

Dichlorvos: This is another organophosphate which is extremely volatile and toxic to man. It has a fumigant as well as a contact effect, and can be used to spray the inside walls of silos before they are filled in the same way as is maldison. It can also be metered into the auger stream during filling at the rate shown in Table 1. Precautions include the wearing of fully protective clothing and a respirator equipped with the correct canister.* It must be stored away from foodstuffs and kept out of reach of children in a locked poison cupboard. Empty containers must be destroyed by being buried $2 \mathrm{ft}$ deep. Dichlorvos cold fog can be used in the pre-season clean-up of header harvesters and augers. Impregnated strips can also be suspended from ceilings of silos and empty bins (Table 1).

Phoxim: This is a phosphoric ester which is effective against a wide spectrum of storage insects and has a long residual effect. It lacks odour, but cannot be used for the direct treatment of foodstuffs for stock or human consumption. It can only be used for a pre-season clean-up of empty granaries, silos, warehouses, and flour mills. Industrial products like hides and textiles can be treated directly. Before treatment, silos and storage places must be thoroughly cleaned of remains of last season's harvest. It is poisonous if swallowed or absorbed through the skin, and fully protective clothing of gloves, overalls, and face mask* must be worn during mixture and application, and operators must wash thoroughly with soap and water immediately after application. Operators should work to

*For a schedule of respirators approved for use consult the local Medical Officer of Health. 

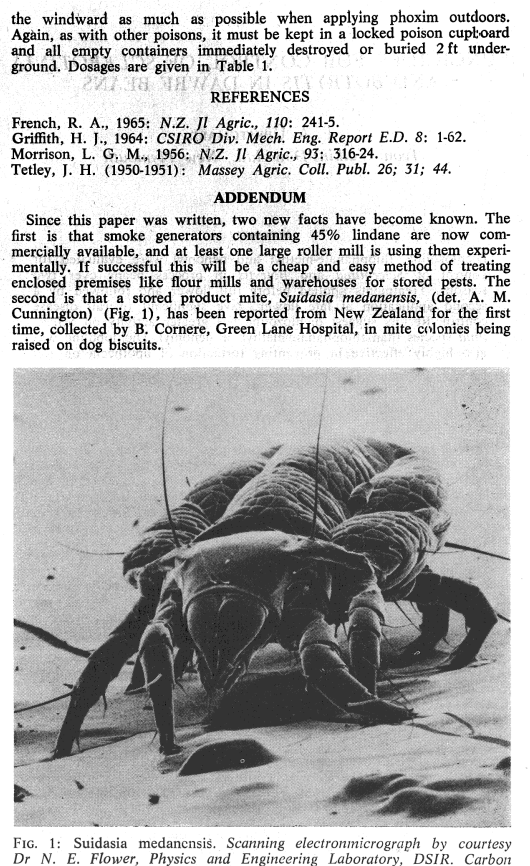

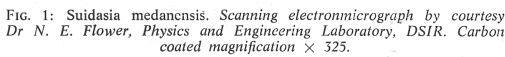

